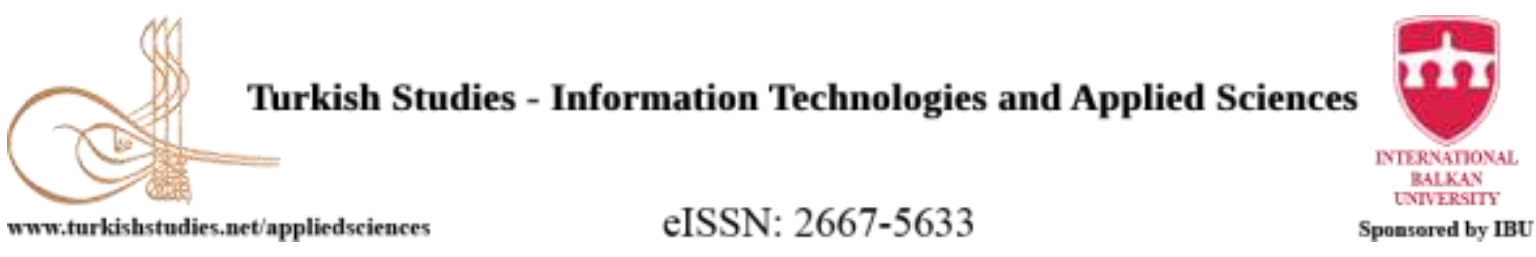

Research Article / Araștırma Makalesi

\title{
Görsel Sanatlar - Yapay Zekâ İş Birliğine Yönelik İşlevsel Sınıflandırma Derlemesi
}

Functional Classification Compilation for the Visual Arts-Artificial Intelligence Collaboration

\author{
Güllü Yakar*
}

\begin{abstract}
Artificial intelligence applications can recognize and evaluate the images and generate new ones by synthesizing them with the help of its subfields - the machine learning and computational creativity-. These applications are capable of classifying artists and their works in terms of creativity scores, evaluating aesthetics or analyze artistic styles; thus, makes it easier to make expertise and prevent forgery. It is also used as a guiding vehicle in the restorations or digital archieve organization processes with its mentioned properties. Artificial intelligence has a potential to produce creative and aesthetic artworks. It can make style transfer, emotional modelling, text-to-image generation or create photorealistic images from sketches by adding them perspective and texture. By accessing online databases, these algorithms are capable of compiling from the resources related to the work it will create, improving itself or producing more advanced versions of itself. Artificial intelligence artifacts with the characteristic of an artist or a movement, or of a unique quality outside of the existing styles, are being exhibited at museums and galleries. Having an impact on a large part of modern life, this technology is a tool open to experimentation which can be used to reach the limits of artistic experiences and to create original components. It is a new area for examining the identity of the contemporary artist and work of art, and for explicating modern concepts. Artificial intelligence is an advanced assistant which is capable of reflecting the spirit of the age to the work of art; and is the novel form of expression for conceptual art. This study aims to classify the researches and projects of visual arts-artificial intelligence collaboration. As a result of the literature review, it was determined that the mentioned works were prepared to perform one of the two main functions: artwork analysis or synthesis. This study is shaped accordingly; following the section on the artificial intelligence's methods of artistic analysis, its image synthesizing methods are explained.
\end{abstract}

Structured Abstract: Studies on artificial intelligence are progressing in parallel with the industrial developments. The first examples that can make artistic production were the mechanical automats developed during the Industrial Revolution Period. The drawings and calligraphy applications created with templates by these automats can be evaluated as reproduction. In parallel with aims of the age, these automats were mimicking human motor skills. With the advent of Industry 4.0 which is the last Industrial Revolution; learning, decision making and creative aspects of the machine have been improved. The terms such as machine learning, dream, computational creativity, computer vision, pattern recognition, neural network, image processing are indicating that artificial intelligence is a simulation of the human mind. In other words, rather than its physical traits, human cognitive skills and aesthetic perception are now being imitated.

Artificial intelligence applications can evaluate works of art in terms of originality or similarities with other works and can score their creativity levels; with these functions, it enables the development of the digital archives of museums, galleries or image providing websites and allows users to scan in detail and explore the

\footnotetext{
${ }^{*}$ Dr. Öğr. Üyesi, Necmettin Erbakan Üniversitesi, Güzel Sanatlar Fakültesi, Grafik Bölümü Asst. Prof. Dr., Necmettin Erbakan University, Faculty of Fine Arts, Department of Graphic ORCiD 0000-0002-1272-5012

gyakar@erbakan.edu.tr

Cite as/ Atıf: Yakar, G. (2020). Görsel sanatlar-yapay zekâ iş birliğine yönelik işlevsel sınıflandırma derlemesi. Turkish

Studies - Applied Sciences, 15(3), 373-388. https://dx.doi.org/10.47844/TurkishStudies.43972

Received/Geliş: 04 June/Haziran 2020

Checked by plagiarism software

Accepted/Kabul: 20 September/Eylül 2020

Published/Yayın: 25 September/Eylül2020

Copyright $\odot$ INTAC LTD, Turkey

CC BY-NC 4.0
} 
links between different works. These functions are also valuable for restoration applications. Researches in which artificial intelligence applications are used in tasks such as detecting unknown relationships between works and determining the originality, constitutes the artistic analysis dimension of artificial intelligence. It is a possibility that in the future this function will be used in the evaluation of artistic portfolios. As in the case of applications that determine the plagiarism levels of scientific study reports, it can be envisaged that the portfolios of art and design students can be evaluated in this way.

Artificial intelligence's inputs of the learning sets presented for its analysis function, can be seen as preparation for the synthesis phase. Training the machine to analyse allows it to gain equipment to create new components. Artificial intelligence can create new components from the artworks that it analyses, or deviate from the styles it has learned and instead create a unique style. It can improve the artwork by applying style transfer and adding perspective-texture. It can visualize text or speech. By determining the emotional expression in portraits, it can create appropriate visual fiction. It is possible to evaluate these functions as a transition between the stages of generation and creation. Although it is not possible to mention a pioneering work that can be defined as creation, it is possible to talk about a more advanced skill, originality and experimentation than pure reproduction. In the contemporary artistic understanding; the importance of reaching new components, questioning on the artist's identity, examining the modern concepts enhances the significance of the artificial intelligence artworks. It is also seen that the artists working with artificial intelligence make conscious mistakes in programming to break the perception of perfection. Thus, the artwork is completed with the invisible signature of the artist. Artificial intelligence applications that are still in their low educational level do not show high skill in gathering images together, it creates entangled figures with undefined borders and anatomical defects. It is seen that the artists use this deformed expression consciously and consider this style as the new form of machine aesthetics. In this context, artificial intelligence can convey traces of its artist and produce works that are suitable for the aesthetic understanding of contemporary digital art.

Artificial intelligence is an automation process that can reproduce itself as well as producing works of art. However, the fact that the authority of intervention is in the human user keeps artificial intelligence to remain as a tool for now. It is considered to be a remote possibility that the works it produces can be uniform. Just as Arts and Crafts Movement created a new aesthetic approach against the soulless industrial production in the 19th century; it is possible for artworks of artificial intelligence to turn into authentic styles in case they become uniform.

It is necessary to examine the findings of many disciplines in order to be able to question the actions of an algorithm in the framework of creativity which can decide on the content it will produce, operate autonomously and develop itself. A more rational approach can be developed for today's conditions by moving beyond the artistic or technological aspect of the subject and rather examining it within philosophical or legal contexts. In cases of plagiarism and violation of personal rights or copyrighted materials; the real person (programmers etc.) will be responsible, not the productive algorithm. The fact that the initial programmer is human makes it an absolute partner of the production process. When analysed in a philosophical context, it can be argued that the autonomous algorithm, the first producer of which was human, could not be fully autonomous -even though it could recode itself- or that human beings could transfer their right by giving autonomy to the machine. As long as the terms are human-oriented, the production of artificial intelligence will not be able to move beyond this axis. Therefore, the existing assessments need to be reconsidered in the light of new developments.

Artificial intelligence has a more competent artistic potential in image production-processing, style transfer or artistic style imitation. It is a tool with a large capacity to evaluate various types of data such as image, sound and mood together, to apply or reject the rules, compile from updated databases. It can improve its creative skills in a controlled manner in order to move beyond the existing styles and to keep the audience's attention. It is an assistant which is capable of making independent decisions at the planned level and period, and editing the data to be used. Although the machine's ability to make independent decisions opens up a discussion on the artist's level of influence on the artwork; as long as the programmer is human, it is not possible to claim that it is the machine which produces the work. However, an artificial intelligence application whose field of control is expanded in the decision-making process can bring about experimental results.

Keywords: Visual Arts, Artificial Intelligence, Computational Creativity, Machine Learning, Style Transfer 
Öz: Yapay zekâ, alt alanları olan makine öğrenmesi ve hesaplamalı yaratıcılık uygulamaları aracılığıyla; görüntüleri tanıyıp değerlendirebilmekte ve bunları sentezleyip yeni görüntüler üretebilmektedir. Bu uygulamalar; sanatçıları ve eserlerini yaratıcılık skorları bakımından sınıflandırabilmekte, estetik değerlendirme yapabilmekte, artistik üslupları analiz edebilmektedir. Böylece ekspertiz yapabilmeyi ve sahteciliğin engellenmesini kolaylaştırmaktadır. Bahsedilen işlevleriyle, restorasyon çalışmalarında ya da dijital sanat arşivlerinin düzenlenmesinde kılavuz araç olarak kullanılmaktadır. Yapay zekâ, yaratıcı ve estetik sanat yapıtları ortaya koyabilme potansiyeline sahiptir. Stil transferi, duygusal modelleme, metinden görüntü üretimi yapabilmekte; basit eskizleri perspektif ve doku ekleyerek fotogerçekçi hale getirebilmektedir. Bu algoritmalar, çevrimiçi veri tabanlarına erişerek; oluşturacağı esere ilişsin kaynaklardan derleme yapabilmekte, kendi kendini geliştirebilmekte ya da daha gelişmiş versiyonlarını üretebilmektedir. Bir sanatçının veya akımın karakteristik özelliklerini taşıyan ya da mevcut üslupların dışında benzersiz nitelikteki yapay zekâ ürünü eserler, müze ve galerilerde izleyici karşısına çıkmaktadır. Modern hayatın geniş bir bölümünde etki yaratan bu teknoloji; sanatın sınır deneyimlerine ulaşmakta, özgün bileşkeler oluşturmakta faydalanılabilecek, deneyselliğe açık bir araçtır. Çağdaş sanatçının kimliğinin ya da sanat eserinin sorgulanması, modern kavramların irdelenmesi için yeni bir alandır. Yapay zekâ, çağın ruhunu sanat eserine yansıtabilecek gelişmiş bir asistan ve kavramsal sanatın yeni anlatım biçimidir. Çalışma, görsel sanatlar-yapay zekâ iş birlikli araştırma ve projelerin sınıflandırılması amacıyla hazırlanmıştır. Literatür taraması neticesinde, bahsedilen çalışmaların; sanat eseri analizi ya da eser sentezleme olmak üzere iki temel işlevden birisini açıklamak üzere hazırlandığı görülmüştür. Çalışma bu doğrultuda şekillendirilmiş olup; yapay zekânın sanat eserlerini analiz etme biçimlerinin ardından, görüntü sentezleme biçimleri açıklanmıştır.

Anahtar Kelimeler: Görsel Sanatlar, Yapay Zekâ, Hesaplamalı Yaratıcılık, Makine Öğrenmesi, Stil Transferi

\section{Giriş}

Teknoloji, insan hayatının diğer tüm alanlarını olduğu gibi sanat ve sanata ilişkin kavramlarını da dönüşüme uğratmıştır. Geleneksel çizim ve boyama teknikleri kullanılmaya devam edilmekle birlikte, bunların kompleks bir simülasyonu niteliğindeki bilgisayar programlarına yönelimin arttığı görülmektedir. 21. Yüzyıl teknolojisi ile oluşturulan görsel sanatlar-yapay zekâ iş birliği ise salt simülasyondan çok daha ileri bir noktadadır. Dijital teknoloji kullanımının sanata etkilerine yönelik tartışmaların azaldığı 21 . Yüzyıl'da; sanatçının konumu tartışılmaya başlanmıştır. $\mathrm{Bu}$ tartışma, sanatta otonomlaşma ve yapay zekâ ile gündeme gelmiştir ${ }^{1}$. İnsana dair yaratıcılık ve karar alma süreçlerinin makineye aktarılıp aktarılamayacağ teşkil etmektedir. Benzer kaygıların, sanat tarihinde pek çok kez yaşandığ öğrenmesi ${ }^{2}$ ve dijital fotoğrafçılık alanında çalışan Blaise Agüera y Arcas; görsel sanatlar-yapay zekâ iş birliğinin bugünkü durumunu, fotoğraf makinesinin gelişimi ile özdeşleştirmektedir. y Arcas (2017), günümüz yapay zekâ üretimlerinin sanat eseri olup olmadığına ilişkin sorgulamanın benzerinin 19. Yüzyıl'da çekilen ilk fotoğraflar için de yapıldığını; yapay zekâ üretimi eserlerin de fotoğraf gibi sahtelik-gerçeklik eleştirisine maruz kalacağını ifade etmektedir. Fotoğraf teknolojisi gelişiminin ilk safhalarında, sanatsal yetkinlik sergilemeyen çoğaltımlar elde edilmiştir. Günümüzde fotoğraf, sanatsal bir anlatım biçimi olarak kabul edilmektedir. Analog çekim tekniklerinden dijital teknolojiye geçişin de yine benzer kaygılar yarattığı görülmektedir. Fotoğrafın, kendine has bir düşünme süreci sonunda elde edilmesi ve gerçekliğin temsili olması gerektiği; bu niteliklerin dijital teknolojiyle bozumsamaya uğradığı yönünde görüşler mevcuttur (Çimen, 2020: 22, 26).

Sanatta dijitalleşmenin etkileri tartışılmaya devam ederken; araştırma bulguları, makineye insansı nitelikler kazandırma sürecinin hızla geliştiğini göstermektedir. Yapay zekânın görüntü işleme bakımından bulunduğu nokta şu şekilde açıklanabilir:

\footnotetext{
${ }^{1}$ Sanatçı, sanat tarihçisi, yazılım geliştirici ve veri analisti uzmanların iş birlikli çalışması ile sanatsal üretim için yapılandırılan bir yapay zekâ sistemi; karar verme ve uygulama süreçlerini otonom biçimde gerçekleştirebilir.

${ }_{2}^{2}$ Makine öğrenmesi: Veri setleri üzerinden tekrarlanan eğitimlerle değişken ortamlara uyarlanabilen, öngörme ve çözüm sağlama becerisine sahip yapay zekâ temelli programlar geliştirme (Alpaydın, 2016: 17, 161).
} 
İnsanlar, üç boyutlu şekil özelliklerine karşı oldukça hassas olma eğilimindeyken, derin sinir ağları ${ }^{3}$ iki boyutlu görüntü özelliklerine karşı daha hassastır. Derin sinir ağları önemli görsel görevlerde etkileyici performans elde etmişlerdir. Bununla birlikte, bu tür performanslar genellikle basitleştirilmiş eğitim prosedürleri ve insanlar tarafindan zahmetli bir şekilde etiketlenmiş veri kümeleri kullanılarak elde edilmiştir. Gelecekteki yapay zekâ araştırmacılarının derin sinir ağlarını daha insani hale getirebilmeleri için eklemeler (örneğin görsel dikkat, bellek ve soyutlama) yapmaları gerektiği öngörülmektedir (Jacobs \& Bates, 2018: 4, 5).

Çalışma, görsel sanatlar-yapay zekâ iş birliği türlerinin işlevsel bakımdan sınıflandırılması üzerine kuruludur. İlk bölümde yapay zekânın tanıma, sınıflama, sıralama gibi analize yönelik işlevleri sunulmuş; ikinci bölümde yapay zekânın taklitten özgün eser yaratmaya uzanan sentez işlevleri sıralandırılmıştır.

\section{Görsel Sanatlar-Yapay Zekâ İş Birliği Türleri}

Yapay zekâ ile ilgili çalışmalar endüstriyel gelişimle paralel biçimde ilerlemektedir. Sanatsal üretim yapabilen ilk örnekler, Sanayi Devrimi Dönemi'nde geliştirilen mekanik otomatlardır. Bu otomatların şablonlarla oluşturduğu çizimler ve kaligrafi uygulamaları çoğaltım olarak değerlendirilebilir. Dönemin amaçlarıyla paralel biçimde bu otomatlar insanın motor becerilerini taklit etmektedir. Son Sanayi Devrimi olan Endüstri 4.0 ile birlikte; makinenin öğrenen, karar alan, yaratıcı yönleri geliştirilmiştir. Makine öğrenmesi, rüya, hesaplamalı yaratıcılık, bilgisayar görüşü, örüntü tanıma, sinir ağı, görüntü işleme gibi terimler; yapay zekânın insan zihninin simülasyonu olduğunu göstermektedir. Diğer bir ifadeyle artık insanın fiziksel değil bilişsel becerileri ve estetik algisı taklit edilmektedir.

Yapay zekânın sanatsal yaratımı, genel olarak makine öğrenmesiyle eğitilen otonomların çıktılarını kapsar. Smith ve Leymarie (2017) görsel sanatlara entegre edilmiş otonomları şu şekilde siniflandırmaktadır:

1. Sofistike hareket ve davranışlarıyla bir performans sanatçısı olarak ele alınabilecek kinetik ya da robotik donanımlar,

2. Çarpıcı soyut çalışmalar yaratabilen otonomlar ve boyama robotları,

3. Modellerin portrelerini çizebilen, grafiksel stillerle yorumlayabilen robotlar,

4. Eserin stilinden sanatçısını ya da dönemini tahmin edebilen yapay zekâ sistemleri,

5. Verilen bir sanat eserinin stilini algılayıp farklı bir görüntüye estetik biçimde uygulayabilen hesaplamalı yapay zekâ sistemleri (Smith \& Leymarie, 2017: 1).

Resim yapan robotik donanımlar ${ }^{4}$ çalışmada ele alınmayacak olmakla birlikte; sanatsal üretime yaratıc1 boyutta katılan önemli bir algoritma olan AARON'dan k1saca bahsetmek mümkündür. Sanatsal çalışmalar oluşturmak için tasarlanan bir bilgisayar programı olan AARON; ürettiği stilistik tutarlığa sahip çizimleri kağıt ya da tuval üzerine yazdırabilecek niteliktedir. AARON, 20. Yüzyılın sonunda üretilmiş olması sebebiyle bu alanın öncüleri arasında görülmekte ve yeni nesil yazılımlara örnek oluşturmaktadır.

\footnotetext{
${ }^{3}$ Derin Sinir Ağları (Deep Neural Network [DNN]); görsel algı, konuşma tanıma, metinden metne dil çevirisi gibi oldukça geniş bir alanda performans sunan yapay zekâ sistemleridir (Jacobs \& Bates, 2018: 1).

${ }^{4}$ Tam otomatik bir resim makinesi olan Draughtsman (Artist [Sanatçı]) (18. yy.), hareketlerinin saat mekanizması benzeri bir donanımla yönetildiği bir öz devinim sistemine sahiptir. Juvenile Artist (Genç Sanatçı) (19. yy.) yazı yazabilen ve çizim yapabilen bir otomattır. Callibot (21. yy.), Çin kaligrafisinden örnekler veren bir robottur. Hemingway, el yazısı taklit edebilen bir yapay zekâ robotu (Marr, 2019), CloudPainter, TAIDA ve E-David (Electronic Drawing Apparatus for Vivid Image Display [Canlı İmaj Görüntüleme için Elektronik Çizim Aparat1]) robotik kollarla resim yapabilen yazılım-donanım sistemleridir (Gülzow vd., 2018: 2-5).
} 
Yapay zekâ, otonom işlemlerle sınırlandırılamayacak kadar geniş bir çalışma alanıdır. Sanatla entegrasyonunda taklitten öğrenmeye, bağımsız karar alabilmeye kadar çeşitli seviyelerde kullanılabilmektedir.

Bilgisayar tarafından oluşturulan soyut resimleri görsel karmaşıklıklarından ziyade hesaplama karmaşıklıklarına göre dört seviyeye ayırabiliriz.

Seviye 1, sürecin tamamında insan katılımına ihtiyaç duyan bir boyama yazılımını ifade eder. İlk olarak, yazılım üreticisi manuel veya otomatik olarak üretilen çeşitli görsel bileşenleri hazırlar. Kullanıcılar; yazılım tarafından sağlanan dijital firçayı kullanarak görsel bileşenleri seçebilir veya çizebilir, görsel nitelikleri gerektiği gibi değiştirebilirler.

Seviye 2'nin en iyi temsilcisi fraktal sanattır. Fraktallar, kullanıcıların girdi olarak çeşitli nitelikler, stiller ve matematiksel formüller sağlamasını gerektirir. Programlanmış bir bilgisayar, bu girdilerle otomatik olarak sonuç üretebilir. Başka bir deyişle, Seviye 2'de sonuçlar genellikle belirli rastgele derecelerle parametreleştirilen matematiksel formüllere dayanılarak üretilir.

Seviye 3 'teki yöntemler genellikle bilgiye dayalı makine zekâsı kullanılan sezgisel tarama temeline dayanır. $\mathrm{Bu}$ düzeyde soyut resim üretiminde; üretken yöntem ve dönüşümsel yöntem olmak üzere iki genel yaklaşım vardır. Üretken yöntemi kullanan sanatçılar stillerini hesaplama kurallarına veya algoritmalarına kodlar. Dönüşümsel yöntemi kullanan sanatçılar, görüntü işleme tekniklerini kullanarak dijital görüntüleri soyut resimlere dönüştürür. Örneğin, bir dönüştürme yöntemi firça konturlarını veya dokularını taklit edebilir ve bunları soyut bir resme dönüştürmek için giriş görüntüsüne uygulayabilir.

Seviye 4; yaratıcı sanatsal ve tasarım formlar oluşturmada kullanılan yapay zekâ destekli uygulamaları kapsar. Bu uygulamalar, mevcut resimlerden belirli stilleri algılar ve otomatik olarak objektif bir estetik değerlendirme yapar. Sonuçlar izleyicilerin duygusal ve kültürel arka planlarına uyarlanabilir olur (Bo vd., 2018: 10-11).

\section{Görüntü analizi} incelenmiştir.

Bu bölümde, yapay zekânın sanat eserlerini analiz etme biçimlerini konu alan çalışmalar

\subsection{Artistik Stil Tanıma-Ayırma}

Sanat eserlerinin görsel niteliklerini betimlemek, eserler arasındaki benzerlikleri ölçmek ve modellemek, ilişkiselliği metrik yaklaşımlarla tespit etmek için yapay zekâya artistik stiller tanıtılmaktadır. Eserin stilini, türünü ve sanatçısını öğrenen yapay zekâ algoritmalar1 ${ }^{5}$; anlam bilimsel ve estetik düzlemde analiz yapabilmektedir. Bu algoritmalar; müze ve galerilerin dijital görsel sanatlar koleksiyonlarının ya da görüntü sağlayan web sitelerinin arşivlerinin düzenlenmesini, kullanıcıların detaylı taramalar yapabilmesini, eserler arasındaki ilişkileri keşfedebilmesini kolaylaştırmak için kullanılmaktadır. Yapay zekâ uygulamaları, sanatçıların özgün üsluplarını öğrenip diğerlerinden ayırma becerisi ile eğitildiklerinde; öğrenme setinde tanımlanmamış bir eseri kimliklendirebilmektedir. Uygulamalar, bu işlevleriyle; sahtecilik tespiti yapmakta ya da eserin orijinalliğini tescil etmekte kullanılabilmektedir. Elgammal vd. (2018) tarafindan yürütülen araştırmada; algoritmanın $\% 70$ ile $\% 90$ arasında doğrulukla sahtecilik tespiti yapabildiği raporlanmıştır. Araştırmada Pablo Picasso, Henri Matisse ve Egon Schiele'nin orijinal figüratif eserleri ve deney için özel olarak hazırlanan taklit versiyonları algoritmaya sunulmuştur. 300'e yakın orijinal çizim analiz edilmiş, çizgilerine ayrılmış ve her birinin hangi sanatçıya ait olduğu algoritmaya tanıtılarak, makine öğrenmesi süreci tamamlanmıştır. Algoritma, sanatçıların tipik stillerini şekil, ton, çizgi (kalınlık, yön, tip, basınç vb.) gibi ayırıcı niteliklerle kodlamış ve

\footnotetext{
${ }^{5}$ Algoritma, girdiyi çıktıya dönüştüren talimatlar dizisidir (Alpaydın, 2016: 16).
} 
orijinallerin arasına karıştırılan sahte örnekleri ayırmayı başarabilmiştir. Knowles (2017), bu analiz türünün şu an için fotorealistik resimler yerine yalnızca konturların net olduğu eserleri tanımlayabildiğini; ancak araştırmacıların kalın fırça vuruşları ve benzeri nitelikler içeren İzlenimci eserler üzerinde çalışmalarını sürdürdüklerini ifade etmiştir.

Saleh vd. (2014) tarafından yürütülen çalışmada, sanatçıların birbirlerine etkilerini ve eserlerinin benzerliklerini makine öğrenmesi yoluyla analiz edebilmek için 66 sanatçının 1710 adet eseri incelenmiştir. Rönesans, Barok, İzlenimcilik, Kübizm, Soyut Modern (Soyut Dışavurumculuk, Modern, De Stijl), Dışavurumculuk ve Pop-Art başlıkları altında gruplandırılan resimler; içerik, ekol ve yapılış tarihlerine göre değerlendirilmiştir. Değerlendirme, resimlerdeki anlamsal bilgileri yakalayan Ayrımcı Makine Öğrenme Modeli ve gözlemlenen örnekler ile etiketleri üzerindeki ortak olasılık dağılımını belirleyen Üretken Model yardımıyla gerçekleştirilmiştir. Araştırma sonuçları, makinenin; sanatçıların tarzları arasındaki ilişki düzeylerini, sanat tarihçilerinin görüşleriyle paralel biçimde ortaya koyabildiğini göstermektedir. Bulguların temel referans ${ }^{6}$ listesiyle çoğunlukla tutarlı olduğunu ifade eden araştırmacılar; Gerhard Richter ve David Hockney'in bir bağlantıyı paylaşıp paylaşmadığı ya da Gustav Klimt'in Pablo Picasso veya Georges Braque'tan etkilenip etkilenmediği ${ }^{7}$ gibi soruların makine öğrenmesi yardımıyla yanıtlanabildiğini ifade etmektedir. Frederic Bazille'in Eugene Delacroix'a yakınlığı, Edvard Munch'un Max Beckmann'daki etkisi ya da Edgar Degas'ın Gustave Caillebotte'deki etkisi bulgulanan diğer başarılı eşleme örneklerindendir (Saleh vd., 2014: 3587). Çalışma bulgularını gösteren dağılım grafiğinde Kazimir Malevich, Georgia O’Keeffe, Piet Mondrian ve Mark Rothko gibi isimlerin yığılımdan ayrılmış olması; bu sanatçıların tarzlarındaki benzersizliğin makine öğrenmesi yoluyla da görülebildiğini ortaya koymaktadır. Çalışma, sanat tarihinde daha önce aralarında bağıntı kurulmamış resimler arasındaki benzerliklerin görülmesini de sağlamıştır. Frederic Bazille'e ait Studio 9 Rue de la Condamine (Şekil 1) ve Norman Rockwell'e ait Shuffleton's Barber Shop (Şekil 2) eserleri arasındaki ilişki ilk kez yapay zekâ uygulaması ile ortaya konmuştur. Bu ilişki; kompozisyon kurgusunda, sembolik bağıntılı objelerde ve yapısal elemanlardaki benzerliklerde görülmektedir (Saleh vd., 2014: 3569).
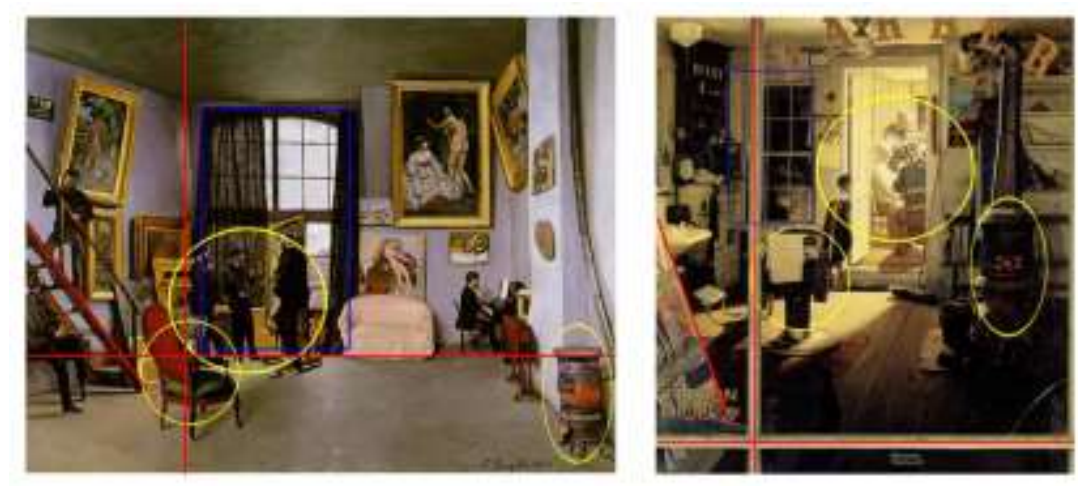

Şekil 1. Frederic Bazille, Studio 9 Rue de la Condamine, 1870, Tuvale Yağlıboya, 98x128 cm.

Şekil 2. Norman Rockwell, Shuffleton's Barber Shop, 1950, Tuvale Yağlıboya, 84x78 cm.

\footnotetext{
${ }^{6}$ Temel referans olarak çevrilen ground-truth terimi; makine öğreniminin sonuçlarını gerçek dünyaya karşı doğruluk açısından kontrol etmek, çalışma bulgularını doğrudan gözlemle edinilen bulgularla sınamak olarak açıklanabilir.

${ }^{7}$ Çalışmada Gustav Klimt'in Pablo Picasso'dan, Picasso'nun Georges Braque’tan etkilendiğine yönelik bulgu rapor edilmiş olması; Braque'ın Klimt'e etkisini dolaylı kılmaktadır.
} 


\subsection{Estetik Değerlendirme}

Yapay zekâ; sanat eserlerinin yaratıcılıklarına göre sıralanması, puanlandırılması gibi çalışmalarda kullanılabilmektedir. Elgammal ve Saleh'in (2015) Wikiart ve Artchieve adlı sitelerden derledikleri bir görsel veri tabanı yardımıyla yürüttükleri araştırma, bu konuda örnek gösterilebilir. Çalışma için geliştirilen Creativity Implication Network (Yaratıcılık Uygulama Ağı) bilgisayarlı (hesaplamalı) yaratıcılık ${ }^{8}$ temellidir. Araştırma, yaratıcılığın tanımındaki iki önemli kavram olan özgünlük ve etki yaratma üzerine şekillendirilmiştir. Algoritma konu ve renk gibi kriterlerle çağdaşlarından ayrılan; sonraki dönemlere öncülük eden eserleri seçmek üzere yapılandırılmıştır. Değerlendirme, resimlerin görsel analizi ve yapılış tarihleri dikkate alınarak gerçekleştirilmiştir. Çalışmada algoritmaya sanat tarihi hakkında hiçbir girdi kodlanmamıştır. Algoritma, sanat tarihi uzmanlarınca hangi eserin başarılı ya da önemli olarak addedildiği bilgisine sahip olmadan değerlendirme yapmıştır. Buna rağmen algoritmanın çoğu durumda, sanat tarihçilerinin gerçekten yenilikçi ve etkili olduğunu vurguladığı bir sanat eserine yüksek puan verdiği görülmüştür. Ancak algoritmanın sanat tarihçilerinin işaret ettiği hususlarla uyuşmayan sonuçlara ulaştığı da görülmektedir. Örneğin algoritma Domenico Ghirlandaio'nun Son Akşam Yemeği'ne (1476-1480), Leonardo da Vinci'nin geç tarihli (1495-1498) ünlü freskinden daha yüksek bir puan vermiştir. Algoritmanın ulaştığı -sanat tarihçilerinin hemfikir olmadığı- bu sonucu, yaratıcılığın buluş ve benzersizlikle ilişkili olmasıyla açıklamak mümkündür. Ghirlandio'nun eserinin daha erken tarihli olması, yaratıcılık puanının yüksek olmasını sağlamıştır. Araştırmacıların "zaman makinesi deneyi” olarak adlandırdığı, algoritmanın kasıtlı olarak yanlış eğitilmesi üzerine kurulu bir düzenekle sonuçların geçerliği sınanmıştır. Döneminde öncü olan eserlerin daha geç tarihlerde yaratılmış gibi gösterilmesi durumunda, eserlerin yaratıcılık skorlarının düştüğ̈̈; eseri, yaratıldığı tarihten daha önce yaratılmış gibi göstermenin yaratıcılık skorunu arttırdı̆̆g gözlenmiştir. "Empresyonist, PostEmpresyonist, Ekspresyonist ve Kübist resimler MS. 1600'lere tarihlendirildiklerinde yaratıcıllk puanlarının arttığı görülmüştür. Rönesans ve Barok üsluplarındaki resimler 1900'lere getirildiğinde yaratıcılık puanları kayba uğramıştır" (Elgammal \& Saleh, 2015: 12, 21). Bulgular, yeterli büyüklükte koleksiyonlarla eğitilen algoritmaların; yaratıc1, özgün ve etkili sayılan resimleri başarıyla vurgulayabildiğini göstermektedir.

\subsection{Restorasyon}

Sanat eserlerinin analiz ve restorasyonu için gereken yüksek çözünürlüklü görüntüleme verileri yapay zekâ ile işlenmektedir. Gent Altar Panosu restorasyonu için yapılan 2019 tarihli görüntüleme çalışması bu kullanımına örnektir. 1432'de Hubert ve Jan Van Eyck kardeşler tarafından yapılan eserin poliptik kanatlarının her iki yüzünde de resim olması, analiz aşamasında röntgen görüntülerinin ayrıştırılmasını zorlaştırmıştır. Her bir yüzdeki resmin ayrı ayrı kolayca analiz edilebilmesi için derin sinir ağı algoritmalarından faydalanılmıştır. Üst üste binmiş görüntüler, çoklu yüzeyler veya erişilemeyen gizli katmanlar hakkında bilgi sunabileceği görülen yapay zekâ uygulamalarının, analiz edilmeyi bekleyen pek çok sanat eserinde kullanılması mümkündür (Sabetsarvestani vd., 2019). Ayrıca ilerleyen bölümlerde bahsedileceği gibi yapay zekâ, sanatçıların üsluplarını taklit edebilmektedir. Eserlerin, sanatçılarının üsluplarıyla tutarlı biçimde restore edilebilmesinde yapay zekâ destekli uygulamalardan faydalanılmaktadır.

\section{Görüintii Sentezi}

Bu bölümde, yapay zekânın yönergeler doğrultusunda görüntü sentezleyerek eser üretme biçimleri incelenmiştir.

\footnotetext{
${ }^{8}$ Hesaplamalı yaratıcılık (Computational creativity): İnsanlardaki yaratıcı becerileri makineye kazandırmaya yönelik yazılımları kapsayan, yapay zekâ araştırmaları alt alanlarından biri (Colton, 2012: 3). Bu sistemlerde yaratıcı uyarı kullanıcıdan değil makineden gelir, ancak karma bir sistemde uyarı her ikisinden de gelebilir (Ackerman vd., 2017: 10).
} 


\subsection{Stil Transferi}

Bir görüntüyü mevcut bir stille yeniden yorumlamak ya da stili bir görüntüden diğerine aktarmak olarak açıklanabilecek stil transferi; temelde bir doku aktarımı olarak kabul edilmektedir. "Doku transferinin amacı; hedef görüntünün semantik (anlam bilimsel) içeriğini koruyarak, kaynak görüntüden doku sentezlemektir" (Gatsy vd., 2016: 2414). Şekil 3'te, Vincent van Gogh'un Yıldızlı Gece ve Edvard Munch'un Çı̆̆lık tablolarındaki stillerin aynı fotoğrafa uygulanmasıyla elde edilen stil transferleri görülmektedir.
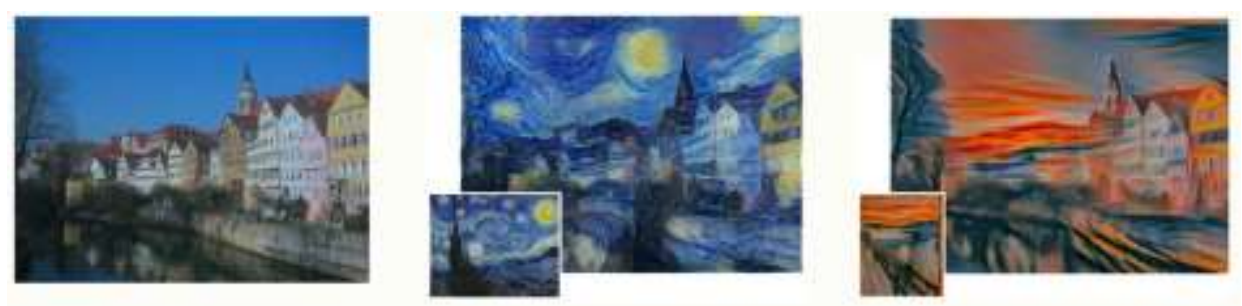

Şekil 3. Fotoğraf (solda), Yıldızlı Gece resminden fotoğrafa stil transferi (ortada), Çı̆̆lık resminden fotoğrafa stil transferi (sağda) (Gatsy vd., 2016: 2418)

Google bilişim şirketinin stil transferi uygulaması DeepDream Generator (Derin Rüya Üreteci); kullanıcı merkezli ve açık erişimli çevrim içi bir görüntü üreteci olup, yapay sinir ağlarının görüntü üretme süreçlerini keşfetmeyi mümkün kılmaktadır.

\subsection{Tanitılan Stilde Eser Üretme}

Yapay zekâ ile sanat eseri üretme ${ }^{9}$ araştırmalarında; sanatçıların ve dönemlerin artistik stillerini taklit edebilmek hedeflenmektedir. Bu konuda ele alınacak araştırmalardan ilki, Wassily Kandinsky stilinde otonom soyut resim üretimi üzerine kuruludur. Kandinsky'nin geometrik formlarla soyut eserler yarattı̆̆ kompozisyonlar serisi; biçim, renk, fon, ritim etkileşimleri bakımından analiz edip kodlanmıştır. Eserlerinde sıklıkla kullandığı keskin açılı sarı renkte formların, koyu renkte dairelerin, çizgilerin ve eğrilerin kesişmesi, birleşmesi, üst üste binmesi gibi nitelikler, zemindeki ton geçişleri ve renk dağılımları detaylı biçimde deşifre edilerek makine öğrenmesine aktarılmıştır (Zhang \& Yu, 2013; Bo vd., 2018). Araştırma sonucunda elde edilen ve sanatçının bu serisindeki çalışmaları taklit eden yeni kompozisyon Şekil 4 'te sunulmuştur.

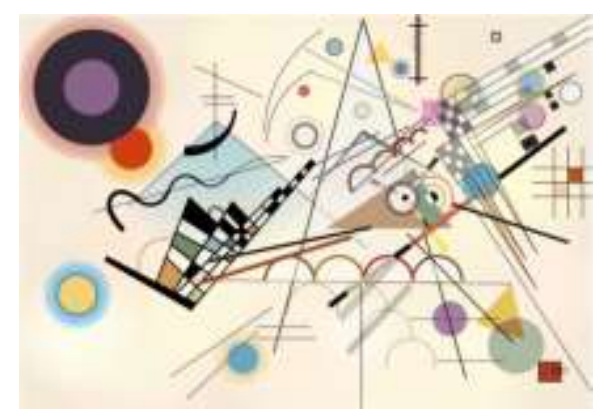

Şekil 4. Kompozisyon VIII (Zhang \& Yu, 2013: 1)

\footnotetext{
${ }^{9}$ Çalışmada üretme kavramı, yaratmanın (yaratıcılığın) bir önceki basamağını betimlemek için kullanılmıştır. Yapay zekâ ile ilgili İngilizce literatürde bu ilişki generate (üretme)-create (yaratma) ayrımıyla yer bulduğu için aktarımda bu ifadeye bağlı kalınmıştır.
} 
Üretilen eserin, yapay zekâ deneyleri arasındaki konumunu gösteren açıklama şu şekildedir:

Bilgisayar tarafından oluşturulan soyut tabloların hesaplama karmaşıklıklarını, yani tablo oluşturulurken makine zekâsının ne ölçüde kullanıldığını ölçen dört seviyeli sınıflandırmaya göre; bir sanatçının stillerini kodlamak için sezgisel kural ve kalıpları kullanıp, ardından sanatçyya özgü resim stilleri oluşturmak Seviye 3'e denk gelmektedir (Zhang \& Yu, 2013: 1).

Araştırmacılar, daha geç tarihli bir raporda çalışmayı "Seviye 4 karmaşıklığına yol açabilecek Seviye 3" olarak tanımlamıştır. Açıklamalar, bahsedilen otomasyonun yapay zekâ için yüksek düzeyde bir beceri kullandığına vurgu yapmaktadır. Raporda, otomasyonun "bilgisayar programlamanın temellerini görsel bir bağlamda öğretmek amacıyla sanatçılar ve tasarımcılar için tasarlandığı" ifade edilmiştir (Zhang \& Yu, 2016: 53).

Makine zekâsına tanitılan stilde otomasyon üretim Jackson Pollock'un boya sıçratma tekniğiyle oluşturduğu fraktal ekspresyonist resimleri (Zheng vd., 2015), Kazimir Malevich'in minimalist soyutlamaları (Tao vd., 2014), Joan Miro'nun organik soyutlamaları (Xiong \& Zhang, 2016) ile tekrarlanmış, otomasyonunun logo tasarımında da istenen sonuçları sağladığı görülmüsstür (Li vd., 2017).

Artistik stil taklidi niteliğindeki araştırmalara ikinci örnek, 2016 tarihli the Next Rembrandt (Gelecek Rembrandt) projesidir. Ölümünün ardından geçen yaklaşık dört yüz yıldan sonra; yapay zekâ, Rembrandt Harmenszoon van Rijn'e yeni bir portre yaptırmıştır (Şekil 5). Proje için sanatçının 346 resmi üç boyutlu tarama ile derin öğrenme ${ }^{10}$ algoritmasına transfer edilmiştir. Portre resimlerinde kullandığı artistik stil ve proporsiyonlar yüz tanıma algoritması ile analiz edilmiş; modellerinin demografik özelikleri ${ }^{11}$, otantik ışık-gölge ifadesi, firça vuruşları ve kompozisyon stili belirlenmiştir. İki boyutlu görüntü tamamlandığında; Rembrandt portrelerindeki firça darbelerinden ve boya katmanlarından gelen üç boyutluluğu eklemek için bir yükseklik haritası oluşturulmuş, üç boyutlu yazıcıda yüksek baskı tekniği ile çıktı alınmıştır (https://www.nextrembrandt.com, 2016).

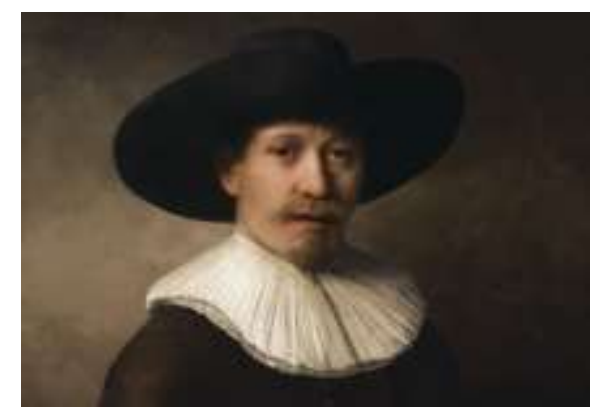

Şekil 5. Gelecek Rembrandt (2016) (https://www.nextrembrandt.com)

\section{3. Özgün Eser Yaratma}

Makinenin özgün eser yaratımının temelinde; yeni bileşkeler oluşturabilmesi, yerleşik stilleri takip etmeyen görüntüler üretmesi vardır. Mevcut artistik üsluplarla eğitilen yapay zekânın, bilinen stil normlarından saparak yaratıcı alanı keşfetmesi amaçlanmaktadır. Bu alanda sıkça karşılaşılan bir sistem olan GAN (Generative Adversarial Networks [Üretici Karşıt Ağlar]), üretici ve ayrımcı olmak

\footnotetext{
${ }^{10}$ Derin öğrenme (Deep learning): Ham girdiden çıktıya kadar çeşitli soyutlama seviyelerine sahip modellerin asgari insan katkısı ile eğitilmesi için kullanılan yöntemler (Alpaydın, 2016: 106, 174).

${ }^{11}$ Rembrandt'ın 1632-1642 yılları arasında yaptı̆̆ portrelerin \%49 kadın, \%51 erkek modelden oluştuğu tespit edilmiş ve projede üretilecek portrenin modelinin erkek olmasına karar verilmiştir. Bu modellerin Kafkas (Beyaz rrka mensup), sakal ve / veya bıyıklı, otuz-kırk yaş aralığında, siyah kıyafet giyen, şapka ve beyaz yaka takan, yüzü sağa dönük olması sebebiyle sanatçının tipik model seçimi-konumlandırması taklit edilmiştir.
} 
üzere birbirine karşıt iki yapay sinir ağına sahiptir. Eğitim setindeki veriye ulaşımı olmayan üretici ağ; rastgele görüntüler üretmekte ve ayrımcının onları gerçek mi, sahte mi bulduğu konusunda ayrımcıdan bir sinyal almaktadır. Ayrımcı ağ; eğitim setindeki görüntülere erişebilmekte, bu setteki gerçek görüntüler ve üretici tarafından oluşturulan sahte görüntüleri karşılaştırabilmektedir. $\mathrm{Bu}$ ağların eksik yönü, üretici ağın yaratıcı motivasyona sahip olmaması sebebiyle mevcut sanat eserlerine benzeyen görüntüler üretmesidir. Üretilen görüntü taklitçi-yaratıcıdır ancak yeni değildir. Örneğin GAN'lar Rönesans, İzlenimcilik veya Kübizm eseri gibi görünen bir sanat eseri üretebilir. Ancak bugün hiçbir yaratıcı sanatçı, ironik bir bağıntı kurmadıysa geleneksel bir tarzı taklit etmeye çalışmamaktadır. Sanatçılar eserlerini yeni, şaşırtıcı, belirsiz kılarak izleyicinin uyarılma düzeyini artırmayı hedeflemektedir. Elgammal vd. (2017) tarafindan sunulan CAN (Creative Adversarial Networks [Yaratıcı Karşıt Ağlar]) sistemi; sanat eserinin çarpıcılığını değişken aralıklarla artırmak üzere tasarlanmıştır. Sistemin çalışma prensibi "Sanat olarak kabul edilenden çok uzağa gitmekten kaçınan, stil belirsizliğini ve stil normlarından sapmaları artırmaya çalışan bir aracı oluşturmak" olarak açıklanmıştır (Elgammal vd., 2017).

Microsoft ile Cambridge Üniversitesi'nin ortaklaşa çalışmaları sonucunda oluşturulan ve 2017 y1lında tanıtılan DeepCoder adlı program, kendi kendini geliştirebilme özelliğine sahiptir. Benzerlerinden farklı olarak; çeşitli programlardan kodlar alıp birleştirebilmekte, bu kodları kendi lehine çevirebilmekte ve ortaya yeni yazılımlar çıkarabilmektedir (www.microsoft.com, 2017). Kendini güncelleyebilecek, diğer bir ifadeyle kendi kendini yeniden üretebilecek bir yazılım; yapay zekânın araç olmaktan çıkacak potansiyel taşıdığını düşündürmektedir. Bu tarz senaryolar; sanatsal, felsefi, bilimsel ve hukuki prensipler doğrultusunda tartışmaya açıktır. Makine, üretme kararını özerk biçimde verebilse ve sanatsal üretim üzerine programlanmış olsa da -bugün için- hukuken kendini temsil hakkı yoktur. İrade ve bilincin mutlak sahibi sayılan insan dışında hiçbir varlığın yasal hak ve sorumluluğu yoktur. Yapay zekâ destekli çalışmalarda telif hakları konusu incelendiğinde (YaniskyRavid, 2017); hukuken sorumlu olanın insan olduğu, kod üreten algoritmanın üretici değil, iş birlikli çalışılan bir eleman olduğu görülmektedir ${ }^{12}$.

Makineye özerk statü kazandırmayı amaçlayan araştırmacılar olduğu gibi, onu bir araç olarak kullandığını belirten sanatçılar olduğu da görülmektedir. Bu sanatçıların eserde fikir, kavram, özgünlük niteliklerine odaklandıkları; ifadede sınır deneyimlere ulaşmayı amaçladıkları görülmektedir. Sanatçılar, mükemmellik algısını kırmak-kusurluluk etkisi katmak amacıyla programlamada bilinçli hatalar oluşturmaktadır (Ridler, 2017). Böylece eser, sanatçının görünmez bir imzasıyla tamamlanabilmektedir. Bu bağlamda yapay zekâ; sanatçısına dair izler aktarabilmekte, çağdaş dijital sanatın estetik anlayışına uygun eserler üretmek için kullanılabilmektedir. Henüz düşük eğitim seviyesinde olan yapay zekâ uygulamaları; görüntüleri bir araya getirmede yüksek beceri gösterememekte; sınırları belirsiz, anatomik kusurları olan, birbirine karışmış figürler oluşturmaktadır. Bu modern sanat trendi GANizm olarak adlandırılmaktadır. Yapay zekâ ile çalışmalar yürüten sanatçıların, bu deformatif ifade biçimini bilinçli olarak kullandıkları; bu tarzı makine estetiğinin yeni bir biçimi (kusurlu bir karşı1ı) olarak ele aldıkları görülmektedir.

\subsection{Duygusal Modelleme}

Yapay zekânın yüz tanıma algoritmaları kullanarak duygudurumlarını öğrenebilmesi, makine-insan etkileşiminin dikkat çekici bir yönüdür. Duygusal ifadeleri görselleştiren imajlar (gülen ya da ağlayan yüzler gibi), bu imajları betimleyen etiketlerle birlikte kodlanarak makine öğrenme süreci tamamlanmaktadır. Böylece yazılımlar farklı duygudurumlarını tanıyabilmekte ve bu duygudrumlarıyla özdeşleşmiş renkleri, çizim stillerini kullanarak artistik ifade oluşturabilmektedir. Bu alandaki çalışmalar arasında Painting Fool (Boyama Aptalı) yazılımı örnek gösterilebilir. Yazılım; görüntüyü renk bölümlerine ayırıp gerçek çizim araçlarını simüle ederek illüstratif çizimler oluşturabilmekte, firça vuruşlarını yön ve basınç bakımından

\footnotetext{
${ }^{12} \mathrm{Bu}$ tarz iş birliği hukuki bağlamda "Work made for hire (Ücret karşıllı̆̆ yapılan iş ya da eser) olarak anılmaktadır.
} 
çeşitlendirebilmektedir. Sahne ya da manzara yapılandırıp boyayabilmekte ve kolaj üretebilmektedir. Mutluluk, üzüntü, korku, şaşırma, öfke, iğrenme gibi duygudurumları çizim stilleriyle eşleştirilerek makineye öğretildiğinde; içeriği geliştirebilecek ifade biçimleri yaratabilmektedir. Kolaj üretmek amacıyla, internetteki metin-görüntü sağlayıcı kaynaklara erişerek materyal toplayabilmektedir. Metin özetleyen yazılımlar yardımıyla, haber metinlerindeki en önemli (sık kullanılan) kelimeleri çıkarıp; bu anahtar kelimelerle internetten görsel arama yapabilmektedir. Elde ettiği görüntüleri, kolaj içinde bir araya getirerek artistik biçimde yorumlayabilmektedir. Süreç sonunda ortaya çıkan örnek kolaj Şekil 6'da sunulmuştur. Sözü geçen kolajın üretimi sürecinde, Painting Fool'un karar verme mekanizmasının bağımsız olarak devreye girdiği ve ilerlediği rapor edilmiştir (Colton, 2012: 30). Afganistan'daki savaş hakkında Guardian Gazetesi'ndeki bir makaleden ilham alan yazılım; makaleden Nato, Birlikler ve İngiliz anahtar kelimelerini çıkardıktan sonra, bu kelimeler için Flickr adlı fotoğraf sağlayıcı siteden görüntüler indirmiştir. Anne ve bebeği, patlama ve bombardıman uçağı gibi imgeler kullanmış, sağ üst köşeye yerel giysili bir kız figürü yerleştirmiş ve savaş bölgelerinde yaşayan insanların durumunu vurgulamak üzere bu figürleri mezarlık imgesiyle yakın biçimde konumlandırmıştır.

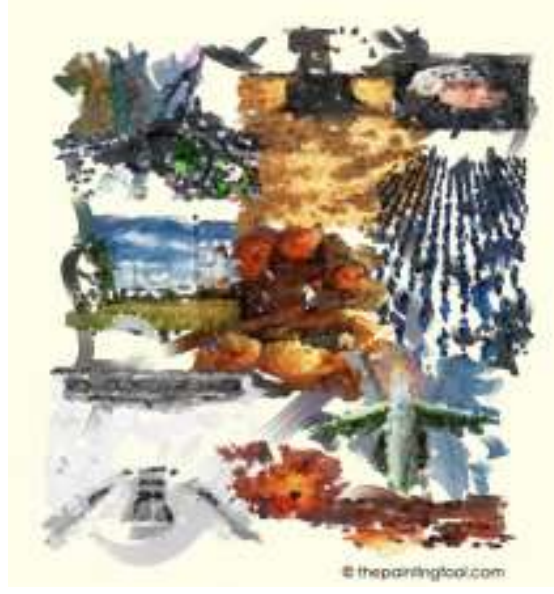

Şekil 6. Painting Fool yazılımının ürettiği kolaj (Colton, 2012: 30)

Painting Fool, karar verme becerileriyle hesaplamalı yaratıcılık alanında yer bulan bir üretici sanat programıdır. Sanatçıların kullanması için bir araç değildir ve bu yüzden bunu mümkün kılmıyoruz. Aksine, gittikçe daha yaratıcı bir şekilde hareket etmek için eğitilmiş bir acemi sanatçı olarak görüyoruz (Colton, 2012).

Norton vd. (2013) tarafından geliştirilen DARCI isimli yapay sinir ağı; parlak, soğuk, ürpertici, mutlu, barışçıl, üzgün, korkutucu, samimi, sıcak, tuhaf gibi sıfatlarla eşleşecek resimler oluşturma becerisi gösteren bir diğer örnektir. Duygudurumlarına uygun biçimde görüntüleri düzenleyebilen ağ; etiketlenen tanımlar doğrultusunda efektler ya da renk filtreleri ekleyebilmekte ve ifadeyle ilişkilendirdiği türde deformasyon uygulayabilmektedir.

\subsection{Yazılı Metinden Görüntü Üretme}

Yapay zekânın sesten yazıya ya da komuta dönüştürme uygulamaları gündelik hayatta sıklıkla kullanılmakla birlikte, metinden görüntü oluşturma uygulamalarının yaygınlaşmadığı belirtilebilir. Bu alanda geliştirilen ağlardan biri olan Dikkatli Genel Üretici A $\breve{g}$ (AttnGAN); doğal dil yapısını kodlamanın yanı sıra, cümle içindeki her kelimeyi de ayrı ayrı kodlamaktadır. Üretken ă̆; birinci aşamada düşük çözünürlüklü bir görüntü oluşturmak için küresel cümle vektörünü kullanmakta, ardından kelime bağlamı vektörünü oluşturmak için her alt bölgedeki görüntü vektörüne inmektedir. Bu anlam bilimsel inceleme süreciyle, her aşamada daha fazla ayrıntı içeren 
daha yüksek çözünürlüklü bir görüntüye ulaşmaktadır. Dikkat mekanizmasıyla, genel cümle seviyesi bilgisini ve detaylı kelime seviyesi bilgisini kullanmakta; oluşturulan görüntü ile cümle arasındaki benzerliği hesaplayabilmektedir (Xu vd., 2018: 1316-1317). Şekil 7 "Gölde yüzen tüylü bir kedi”, "Gölde yüzen kırmızı çift katlı otobüs", "Gölün üstünde yüzen dur işareti” ve "Mavi gökyüzünde süzülen bir dur işareti" ifadelerinin AttnGAN tarafından görselleştirilmesine örnek olarak sunulmuştur.
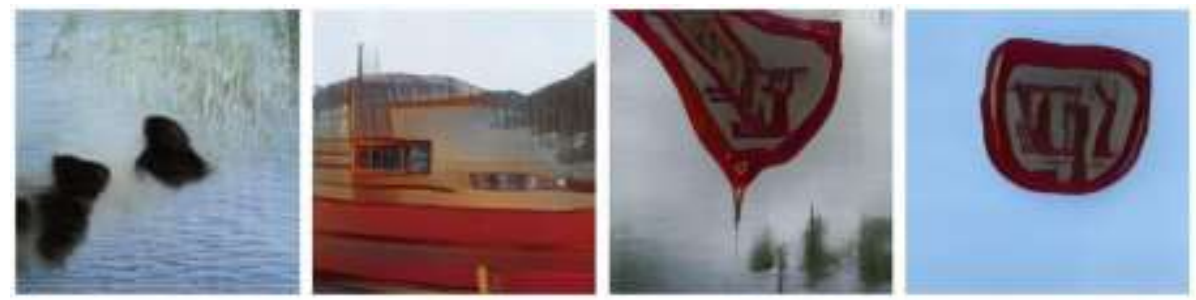

Şekil 7. AttnGAN ile metinden üretilen görüntüler (Xu vd., 2018: 1323)

\section{6. Çizimden Fotogerçekçi Görüntü Üretme}

2019 yılında deneme sürümü tanıtılan, çevrim içi-açık erişimli web uygulaması GauGAN ${ }^{13}$; nihai kullanıcının erişebileceği en yeni yapay zekâ uygulaması örneğidir. Basit eskizlerden fotogerçekçi çalışmalar yaratan bir derin öğrenme modeli olan GauGAN, bu çizimleri anlamsal görüntü sentezleme ile mekâna uyumlayan üretici karşıt ağlar kullanmaktadır. Gerçek dünyanın nasıl göründüğünü anlayabilmesi ve çizimleri mekâna uyarlayabilmesi için; derin öğrenme modeli, bir milyon görüntü üzerinden eğitilmiştir. Görüntüler kum, gökyüzü, çim, deniz, su, yansıma, kar gibi dokularla doldurulmakta ve fotoğraflardan öğrenilen perspektifle modellenerek gerçeklik kazandırılmaktadır. Stil filtreleri sayesinde renk ve 1şık görünümünü değiştirebilen derin öğrenme modeli, görüntüleri gündüzden-gün batımına geniş bir mod çeşitliliğinde sunabilmektedir. Detay ve dokuları, yansımaları, gölgeleri ve renkleri gerçek görüntüler hakkında öğrendiklerine dayanarak doldurmaktadır. Görüntüyü fotogerçekçi perspektif ve dokuyla işleyebilmesi, fotoğraf işleme programı olarak da kullanılabilmesini mümkün kılmaktadır. Bu öğrenme modeli, öncülü olan Pix2Pix ile benzer yönler barındırmaktadır (Park vd., 2019). Şekil 8'de GauGAN uygulaması ile basit çizimlerden elde edilen fotogerçekçi görüntü örnekleri sunulmuştur.

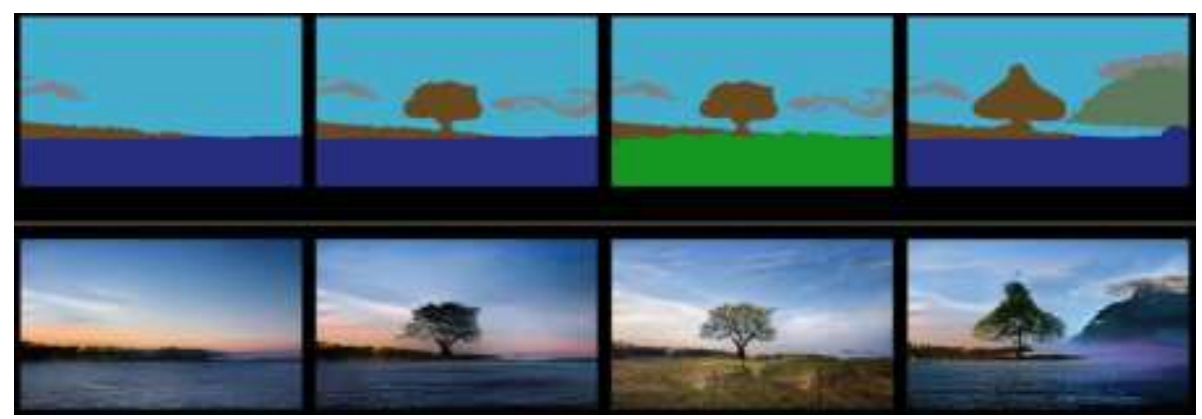

Şekil 8. GauGAN'da görselleştirme örnekleri (Park vd., 2019: 1)

\footnotetext{
${ }^{13}$ GauGAN, Post-Empresyonist sanatçı Paul Gauguin'e ithafen adlandırılmış GAN.
} 


\section{Sonuç}

Yapay zekâ, ilk zamanlarında yalnızca teknik işlemler yürütebiliyorken; günümüzde sanatsal kavramlarla düşünme ve insanın yaratım sürecini taklit etme becerileri kazanmıştır. Bugün bulunduğu konumu, üretme ve yaratma arasında bir öğrenme aşaması olarak ele almak mümkündür. Yaratma düzeyinde değerlendirilebilecek öncü bir eser sunmamış olmakla birlikte; salt çoğaltımdan daha ileri bir beceri sergilediği, özgünlük ve deneyselliği mümkün kıldığı görülmektedir (Ridler, 2017). Günümüz sanat anlayışında yeni bileşkelere ulaşmanın, sanatçı kimliğinin sorgulamaya açılmasının, modern kavramların irdelenmesinin önemli olması; yapay zekâ ile üretilen eserlerin değerini artırmaktadır.

Yapay zekâ uygulamaları yaratıcılık, estetik, görüntü işleme, dil bilimi, anlam bilimi gibi içeriklerle yapılandırılmaktadır. Ancak yaratıcılık ve estetik bilgisi ile donatılan her uygulamanın öncelikli amacı sanat eseri üretmek değildir. Yapay zekâ alt alanları geliştirilirken, sanat da bu deneyimlerden faydalanmaktadır. Yapay ağların, verilen metne uygun olarak oluşturduğu görüntüler temelde sanat eseri değildir; ancak bu görselleştirmeler sanatsal bağlamda kullanılabilir. Sahip olduğu potansiyel sebebiyle sanatçılar yapay zekâ uygulamalarına bilinçli olarak yönelmektedir. Hertzmann, yapay zekâ algoritmalarının; sanatçılar tarafından keşfedilmeye ve kullanılmaya hazır birer araç olduğunu ifade etmektedir. Bu araçlardaki gelişmeler; bazı sanatçılar tarafindan coşkuyla benimsenecek, henüz öngörülemeyen heyecan verici yeni formlara ve stillere yol açacaktır. "Bu, sanatın doğasıdır: Hiçbir şey sonsuza dek yeni olamaz, teknoloji de bundan sorumlu tutulamaz" (Hertzmann, 2018: 15).

Yapay zekâ uygulamaları görüntü, ses, duygudurum gibi çeşitli türde verileri bir arada işleyebilmekte, kuralları uygulayabilmekte ya da reddedebilmekte, güncellenen veri tabanlarından derleme yapabilmektedir. Böylesi geniş kapasiteli bir aracın sanatla birçok farklı düzlemde entegrasyonundan söz etmek mümkündür. İnsan becerisinin kapasitesini aşabilecek ölçekte işlemleri hızlı ve verimli biçimde yürütebilen yapay zekânın; bu işleviyle, asistan olarak hukuki yargılama süreçlerine katılabileceği ifade edilmektedir (Re \& Solow-Niederman, 2019: 255). Görsel sanatlar analizi yapabilen yapay zekânın, gelecekte sanatsal portfolyoların değerlendirmesinde kullanılması olasıdır. Bilimsel çalışma raporlarının intihal düzeylerini ölçen uygulamalar gibi, sanat-tasarım öğrencilerinin portfolyolarının da bu yolla değerlendirilebileceği öngörülebilir.

Yapay zekâ uygulamalarının avantajları genel anlamda kabul görmekle birlikte, insan hayatındaki yeri ve getirileri tartışmalı bir husustur. Bilimsel perspektiften bakıldığında; makine, insanın yapabileceği işleri yürütebilecek potansiyeldedir. Fizikçi Stephen Hawking; biyolojik bir beyin tarafindan elde edilebilecek olanlarla, bir bilgisayar tarafindan elde edilebilecek olanlar arasında derin bir fark olmadığına inandığını ifade etmiştir. Bu ifadeden, bilgisayarların teoride insan zekasını taklit edebileceği ve onu aşabileceği sonucu çıkarılmaktadır (Cellan-Jones, 2016). Yapay sinir ağları, sayısız olasılığı saniyeler içinde hesaplayabilmektedir. Deneyim, bilgi, motivasyon gibi karmaşık gereksinimlere ihtiyaç duymaksızın; insana oranla çok daha kısa bir eğitim süreci ile çalışmaya hazır hale gelmektedir. Duygu, uyarım, sezgi, ilham, yaratma isteği gibi muğlak kavramların hâkim olduğu sanat alanında ise benzer kestirimler yapmak nispeten zordur. Yazılımlar, kuralları önceden belirlenmiş satranç benzeri oyunları oynamakta başarılıdır. Ancak böylesi kuralların olmadığı ve kültürel birikimin önemli olduğu sanatsal alanda yapay zekânın artistik bir oyuncu olup olamayacağı açık değildir (Rugoff'tan akt: Colton, 2012: 20). Yapay zekânın, insanın tüm düşünsel yapısını taklit etmeye çalıştığı görülmektedir. Makine görüşü çalışmaları, insanın görme ve algılama becerilerini simüle etmekte; doğal dil işleme çalışmaları, vurgu ve anlam gibi dolaylı verileri çözümleyebilmektedir. Örneklerden yola çıkarak; motivasyon, sezgi gibi insani unsurların programlanan makineye kazandırılıp kazandırılamayacağı sorgulanabilir. Yapay zekânın sanatsal anlamda yaratıcı kabul edilebilmesi için, insan zihninin işleyişinde ulaşması gereken önemli bağıntılar bulunmaktadır. Bu bağıntılar; sanatçıların öncül deneyimlerinin ve izledikleri sanat 
eserleriyle etkileşimlerinin, yaratıcılıkları üzerindeki etkisidir (Elgammal vd., 2017: 97). Sanatçıların bilgi ve deneyimlerini, üretme yetenekleriyle nasıl bütünleştirdikleri çözümlenebildiğinde; çalışmaların yeni bir boyuta ulaşacağı, yapay zekânın yeni artistik stiller için öngörüde bulunabileceği ifade edilebilir. Bu noktaya ulaşabilmek için; araştırmacıların geniş veri setleri üzerinden zahmetli bir öğretim süreci ile makineyi eğitmeleri ve sanatsal stiller değiştikçe bu eğitimi güncellemeleri gerekmektedir. Ayrıca dikkat, algı ve soyutlama gibi daha karmaşık bilişsel becerilerin bilgisayar görüşüne aktarılabilmesinin önemi vurgulanmaktadır.

Üreteceği içeriğe karar verebilen, otonom biçimde çalışan, kendini geliştirebilen bir algoritmanın eylemlerini yaratıcılık yönünden sorgulamak için pek çok disiplinin bulgularını incelemek gerekmektedir. Zeki makineler yapmak için gereken ipuçlarının felsefe, mantık, biyoloji, psikoloji, istatistik ve mühendislik alanlarına dağılmış olması (Nilsson, 2019: 27); değerlendirmenin bu disiplinlerin verileriyle yürütülebileceğini göstermektedir. Konunun sanatsal ya da teknolojik yönünün dışına çıkılıp; felsefi ya da hukuki düzlemde incelenmesiyle, bugünün şartları için rasyonel bir yaklaşım geliştirilebilir. Üretken algoritmanın, özerk biçimde oluşturduğu çalışma yoluyla; kişilik haklarının ya da telifle korunan materyallerin ihlali, intihal gibi olumsuz durumlara sebep olmas1 mümkündür. $\mathrm{Bu}$ durumda üretken algoritma değil gerçek kişiler sorumlu olacaktır. İlk programlayıcının insan olması, onu üretim sürecinde mutlak bir paydaş yapmaktadır. Felsefi bağlamda incelendiğinde, ilk üreticisi insan olan otonom algoritmanın -kendi kendini yeniden kodlayabilse de- tam anlamıyla özerk olamayacağı ya da insanın makineye özerklik vererek kendi hakkını devredebileceği savunulabilir. Terimler insan eksenli oldukça, yapay zekânın üretimi de bu eksen dışına çıkamayacaktır. Bu sebeple, değerlendirmenin yeni gelişmeler ışığında tekrar ele alınması gerektiği ifade edilebilir.

Sanat güncel gelişmelerin bir yansımasıdır, sanat toplumsaldır. Pablo Picasso 1937 tarihli Guernica adlı eserinde, savaşın yarattığı trajediyi betimlemiştir. Gelecekçi (Fütürist) sanatçılar, Sanayi Devrimi ile belirginleşen makine estetiği kavramını yüceltmiştir. Tüketim kültürünü hicveden Pop Sanat Akımı mensupları; kitlesel üretimle yaygınlaşan reklam görsellerini, çizgi roman karelerini konu edinmiştir (Yılmaz, 2006: 49, 79, 179). Sunulan bu örnekler; sanatçıların ve dolayısıyla sanat akımlarının, dönemlerinin sosyo-kültürel yapısını eserlerine yansıttıklarını göstermektedir. Sanatın yapay zekâyla iş birliği geliştirmesi, ilerleyişin doğal bir parçasıdır. Sürecin geriye işlemesi ve sanatta makine müdahalesinin reddinin savunulması mümkün değildir. Bu da teknolojinin yalnızca sanatta değil insan hayatının hemen her alanında yaratacağı etkiye dair bir gelecek projeksiyonudur. Bugün için, yapay zekâ üretimi eserlerin olası tüm yansımalarıyla sanat çevrelerinde kabul edildiği; hatta müzayedelerde yüksek bedellerle satışa sunulduğu görülmektedir. Eserlerin satış bedelinden daha önemli olan, bu eserlerin müzelerde sergilenmesi ve bu türün tematik ya da karma sergilerde yer bulmasıdır. Bu tarz sansasyonel gelişmeler, yapay zekâ ile sanatsal üretimin modern sanat anlayışındaki yerini ifade etmektedir. Yaratma, mimesis, gerçek ve kurgu kavramlarıyla doğrudan ilişkili olan yapay zekâ çalışmaları; modern estetiğe eklemlenerek, sanat pratiklerini ve sanatın deneyimlenmesini yeni bir seviyeye taşıyacaktır. Tartışmalı bir diğer husus olan fikri mülkiyet ise farklı çalışmaların konusu olarak çözümlenmeyi beklemektedir.

\section{Kaynakça}

Ackerman, M., Goel, A., Johnson, C. G., Jordanous, A., Leon, C., Perez, R. P., Toivonen, H. \& Ventura, D. (2017). Teaching computational creativity. (Eds.) A. Goel, A. Jordanous \& A. Pease, Eighth International Conference on Computational Creativity. (ss. 9-16). Georgia Institute of Technology.

Alpaydın, E. (2016). Machine learning: The new AI. MIT Press. 
Bo, Y., Yu, J. \& Zhang, K. (2018). Computational aesthetics and applications. Visual Computing for Industry, Biomedicine, and Art, 1(6). 1-19. https://doi.org/10.1186/s42492-018-0006-1

Cellan-Jones, R. (2016, Ekim 20). Stephen Hawking: Will AI kill or save humankind? BBC News. https://www.bbc.com/news/technology-37713629

Colton, S. (2012). The painting fool: Stories from building and automated painter. (Eds.) J. McCormack \& M. d'Inverno, Computers and Creativity. (ss. 3-38). Springer.

Çimen, Ü. (2020). Analog fotoğraftan dijital fotoğrafa geçişte fotoğrafik gerçekliğin dönüşümü, $\begin{array}{llll}\text { Turkish } & \text { Studies-Applied } & \text { Sciences, } & \text { 15(1), }\end{array}$ https://dx.doi.org/10.29228/TurkishStudies.40533

Deepcoder (2017). https://www.microsoft.com/en-us/research/publication/deepcoder-learningwrite-programs/. Erişim tarihi: 13.05.2020.

Elgammal, A. \& Saleh, B. (2015). Quantifiying creativity in art networks. (Eds.) H. Toivonen, S. Colton, M. Cook \& D. Ventura. Sixth International Conference on Computational Creativity (ss. 39-46). Brigham Young University.

Elgammal, A., Liu, B., Elhoseiny \& M., Mazzone, M. (2017). CAN: Creative adversarial networks generating art by learning about styles and deviating from style norms. (Eds.) A. Goel, A. Jordanous \& A. Pease. Eighth International Conference on Computational Creativity (ss.96103). Georgia Institute of Technology.

Elgammal, A., Kang, Y. \& Leeuw, M. D. (Şubat 2018). Picasso, Matisse, or a Fake? Automated analysis of drawings at the stroke level for attribution and authentication. AAAI Conference on Artificial Intelligence. New Orleans.

Gatys, L. A., Ecker, A. S. \& Bethge. M. (Haziran 2016). Image style transfer using convolutional neural networks. IEEE Conference on Computer Vision and Pattern Recognition, Las Vegas.

Gelecek Rembrandt. (2016). https://www.nextrembrandt.com. Erişim tarihi: 07.08.2019.

Gülzow, J. M., Gravyer, L. \& Deussen, O. (2018). Self-improving robotic brushstroke replication. Arts, 7(84), 1-28. https://doi.org/10.3390/arts7040084

Hertzmann, A. (2018). Can computers create art? Arts, 7(18), 1-25. https:// doi.org/10.3390/arts7020018

Jacobs, R. A. \& Bates, C. J. (2018). Comparing the visual representations and performance of humans and deep neural networks. Current Directions in Psychological Science, 28(1), 1-6. https://doi.org/10.1177\%2F0963721418801342

Knowles, K. (2017, Kasım 21). This AI spots art fakes in a single brush stroke. http://authenticationinart.org/pdf/artmarket/ai-forgery-detective.pdf Erişim tarihi: 11.10.2019.

Li, Y., Zhang, K. \& Li, D. (2017). Rule-based automatic generation of logo design. Leonardo, 50(2), 177-181. https://doi.org/10.1162/LEON_a_00961

Marr, B. (2019, Haziran 21). Meet Hemingway: The artificial intelligence robot that can copy your handwriting. Forbes. https://www.forbes.com/sites/bernardmarr/2019/06/21/meethemingway-the-artificial-intelligence-robot-that-can-copy-yourhandwriting/\#9de9d7e4dabe Erişim Tarihi: 22.12.2019.

Nilsson, N. J. (2019). Yapay zekâ: Geçmişi ve geleceği (2. baskı). Boğaziçi Üniversitesi Yayınevi. 
Norton, D., Heath, D. \& Ventura, D. (2013). Finding creativity in an artificial artist. The Journal of Creative Behavior, 47(2), 106-124. https://doi.org/10.1002/jocb.27

Park, T., Liu, M, Wang, T. \& Zhu, J. (Haziran 2019). Semantic image synthesis with spatiallyadaptive normalization. CVPR 2019 Conference, Long Beach, CA.

Re, R. M. \& Solow-Niederman, A. (2019). Developing Artificially Intelligent Justice. Stanford Technology Law Review, 22(2), 242-289.

Ridler, A. (2017). Misremembering and Mistranslating: the Associations of GANs in an Art Context. 31 st Conference on Neural Information Processing Systems, Long Beach, CA, USA.

Sabetsarvestani, Z., Sober, B., Higgitt, C., Daubechies, I. \& Rodrigues, M.R.D. (2019). Artificial intelligence for art investigation: Meeting the challenge of separating X-ray images of the Ghent Altarpiece. Science Advances, 5(8), 1-8. https://doi.org/10.1126/sciadv.aaw7416

Saleh, B., Abe, K., Arora, R. S. \& Elgammal, A. (2014). Toward automated discovery of artistic influence. Multimed Tools Appl, 75(7), 3565-3591. https://doi.org/10.1007/s11042-0142193-x

Smith, G. W. \& Leymarie, F. F. (2017). The machine as artist: An introduction. Arts, 6(5), 1-7. https://doi.org/10.3390/arts6020005

Tao, W., Liu, Y. \& Zhang, K. (2014). Automatically generating abstract paintings in Malevich style. (Eds.) Y. Hang, W. Song, S. Xu, L. Chen \& R. Lee. International Conference on Computer and Information Science 2014 (ss. 201-205). Taiyuan, China.

Xiong, L. \& Zhang, K. (Eylül 2016). Generation of Miro's surrealism. (Eds.) A. Kerren \& K. Zhang. VINCI '16: 9th International Symposium on Visual Information Communication and Interaction (ss. 130-137), Dallas.

Xu, T., Zhang, P., Huang, Q., Zhang, H., Gan, Z., Huang, X. \& He, X. (Haziran 2018). AttnGAN: Fine-grained text to image generation with attentional generative adversarial networks. 2018 IEEE/CVF Conference on Computer Vision and Pattern Recognition (ss. 1316-1324), Utah.

Yanisky-Ravid, S. (2017). Generating Rembrandt: Artificial intelligence, copyright, and accountability in the 3A era - the human-like authors are already here - a new model. Michigan State Law Review, 4, 659-726. https://dx.doi.org/10.2139/ssrn.2957722

y Arcas, B. A. (2017). Art in the age of machine intelligence. Arts, 6(18), 1-9. https://doi:10.3390/arts6040018

Y1lmaz, M. (2006). Modernizmden Postmodernizme sanat. Ütopya Yayınevi.

Zhang, K. \& Yu, J. (Kasim 2013). Generating abstract paintings in Kandinsky style. SIGGRAPH Asia 2013 Conference, No: 18, Hong Kong.

Zhang, K. \& Yu, J. (2016). Generation of Kandinsky art. Leonardo, 49(1), 48-54. https://doi.org/10.1162/LEON_a_00908

Zheng, Y., Nie, X., Meng, Z., Feng, W. \& Zhang, K. (2015). Layered modeling and generation of Pollock's drip style. The Visual Computer, 31(5), 589-600. https://doi.org/10.1007/s00371014-0985-7 